\title{
ADMINISTRAÇÃO AGUDA DO ÓLEO ESSENCIAL DE RUTA GRAVEOLENS L. SOBRE A MEMÓRIA E AMNÉSIA CAUSADA PELA ESCOPOLAMINA EM CAMUNDONGOS MACHOS
}

Acute administration of Ruta graveolens L. essential oil on memory and scopolamine-induced memory impairment in male mice

Camila Ângela Zanella ${ }^{1}$; Paula Santana Lunardi²; Tanara Weber ${ }^{1}$; Aline Rosset ${ }^{1}$; Assis Ecker ${ }^{3}$; Carlos Alberto Saraiva Gonçalves ${ }^{2}$; Altemir José Mossi ${ }^{4}$; Rogério Luis Cansian ${ }^{1}$; Silvane Souza Roman ${ }^{1}$

${ }^{1}$ Universidade Regional Integrada do Alto Uruguai e das Missões, Departamento de Ciências Biológicas e Farmácia, URI Erechim. E-mail: roman@uricer.edu.br

${ }^{2}$ Universidade Federal do Rio Grande do Sul, Departamento de Bioquímica, UFRGS - Campus de Porto Alegre.

${ }^{3}$ Universidade Federal de Santa Maria, Departamento de Bioquímica e Toxicologia, UFSM - Campus de Santa Maria.

${ }^{4}$ Universidade Federal da Fronteira Sul, Departamento de Engenharia Agrícola, UFFS - Campus Erechim.

Data do recebimento: 25/10/2019 - Data do aceite: 19/02/2020

RESUMO: A planta medicinal Ruta graveolens L. (RG), popularmente conhecida como arruda, já foi sugerida na literatura com potencial para o desenvolvimento de medicamentos para o tratamento de demência e da doença de Alzheimer. O objetivo deste trabalho foi investigar os efeitos da administração aguda do óleo essencial de RG (100 mg/kg) sobre a memória de curta e longa duração e verificar a reversão da amnésia causada pela escopolamina em camundongos machos. Foram utilizados os testes de campo aberto, esquiva inibitória, labirinto aquático de Morris e avaliada a inibição da enzima acetilcolinesterase cerebral. Os resultados mostraram que uma única administração do óleo essencial de RG não alterou a atividade locomotora no teste de campo aberto, facilitou a aquisição de uma memória de longa duração na tarefa de esquiva inibitória, porém não preveniu a amnésia causada pela escopolamina. O óleo essencial de RG não apresentou efeitos sobre a 
memória de curta duração nem na inibição da acetilcolinesterase no córtex pré-frontal, hipocampo e estriado. No labirinto aquático de Morris não foram observadas alterações em nenhum dos tratamentos. Com base nos resultados obtidos, podemos concluir que o óleo essencial de RG facilitou a aquisição de uma memória aversiva de longa duração.

Palavras-chave: Arruda. Memória. Plantas Medicinais. Ruta graveolens.

\begin{abstract}
Ruta graveolens L. (RG), a medicinal plant popularly known as rue, has been investigated as a potential plant for drug development regarding dementia and Alzheimer's disease treatment. The aim of this study was to investigate the effects of acute administration of RG essential oil $(100 \mathrm{mg} / \mathrm{kg})$ on short and long-term memory and verify the reversal effects of scopolamine-induced memory impairment in male mice. Open field, inhibitory avoidance, Morris water maze behavioral tests were performed and the inhibition of cerebral acetylcholinesterase enzyme was evaluated. The results obtained showed that a single oral administration of RG essential oil did not alter locomotor activity in the open field test, facilitated the acquisition of long-term memory in the inhibitory avoidance task, but did not prevent scopolamine-induced memory impairment. RG essential oil had no effect on short-term memory or acetylcholinesterase inhibition in the prefrontal cortex, hippocampus or striatum. In the Morris water maze, no changes were observed in any of the treatments. Based on the results found in this study it is concluded that RG essential oil single administration facilitated the acquisition of an aversive long-term memory.
\end{abstract}

Keywords: Rue. Memory. Medicinal Plants. Ruta graveolens.

\section{Introdução}

Uma das fontes importantes para o descobrimento de um novo fármaco está na diversidade química dos compostos a serem estudados, cujas fontes podem ser: compostos sintéticos, produtos naturais ou química combinatória. Entre estas possibilidades, os produtos naturais são considerados como uma das maiores fontes de diversidade química, pois, quando utilizados em doses adequadas, podem produzir efeitos biológicos consideráveis (STREGE,1999; BRISKIN, 2000; MONTANARI; BOLZANI, 2001; ARONSON et al., 2012).
A utilização de plantas com fins medicinais, para tratamento, cura e prevenção de doenças, é uma das formas mais antigas de prática medicinal da humanidade. De acordo com a Organização Mundial de Saúde (OMS), cerca de $80 \%$ da população dos países em desenvolvimento dependem de plantas medicinais como única forma de acesso aos cuidados básicos de saúde (WHO, 1991; SEM; SAMANTA, 2015). Em 2019, um estudo realizado no norte do Brasil levantou a importância de armazenar informações referentes às plantas medicinais na memória humana. Saber qual planta medicinal é indicada para qual tratamento de 
doenças poderia ter importância evolutiva (DA SILVA et al., 2019).

A planta medicinal Ruta graveolens L. (RG) é um membro da família Rutaceae e é popularmente conhecida como arruda. Trata-se de um arbusto perene de até um metro de altura, com coloração verde e um odor característico e acentuado. As folhas são pequenas, profundamente divididas e pinadas. Os caules são muito ramificados e suas flores são pequenas e amarelas (ZARGARI, 1990).

Os metabólitos secundários presentes nas plantas são compostos químicos que participam do metabolismo celular e apresentam inúmeros efeitos biológicos e, por esse motivo, são amplamente estudados. Tais compostos podem ser extraídos de diferentes maneiras, entre elas por meio da extração do óleo essencial. Existem diferentes métodos de obtenção de óleos essenciais. Apenas para citar alguns exemplos, encontram-se a hidrodestilação, destilação a vapor e extração por fluido supercrítico (AZIZ et al., 2018; AGATONOVIC-KUSTRIN et al., 2019).

Diferentes estudos demonstraram que a $\mathrm{RG}$ apresenta atividade antimicrobiana, fungicida (OLIVA et al., 2003; MEEPAGALA et al., 2005; IVANOVA et al., 2005), anti-inflamatória, antipirética, antinociceptiva (RAGHAV et al., 2006; LOONAT; AMABEOKU, 2014), propriedades hipotensoras (CHIU; FUNG, 1997) e eficácia na contracepção (MAURYA et al., 2004).

Entre outras plantas, a RG já foi sugerida como uma nova candidata para o desenvolvimento de medicamentos para o tratamento da demência e a doença de Alzheimer por sua possível atividade inibitória da enzima acetilcolinesterase (AChE) (RUSSO et al., 2013; AGATONOVIC-KUSTRIN et al., 2019). A AChE é a enzima responsável pela degradação do neurotransmissor acetilcolina. A acetilcolina é um importante neuromodulador envolvido com a formação de memórias (SMITH, 1988; FIBIGER, 1991; TAYLOR; BROWN, 1994; SCREMIN et al., 1997; LIKHTIK; JOHANSEN, 2019). Embora existam muitos fatores atribuídos ao desenvolvimento da doença de Alzheimer, a degeneração de neurônios colinérgicos (que acarreta a diminuição da acetilcolina) é um dos fatores responsáveis pela perda de memória característica da doença. Logo, entre as ferramentas farmacológicas paliativas disponíveis para o tratamento da doença de Alzheimer, alguns fármacos visam a aumentar o nível de acetilcolina no cérebro, contudo, apresentam efeitos colaterais (BOWEN et al., 1979; NOWOTNY et al., 2001; LANE et al., 2018).

A memória é uma das mais importantes funções cognitivas do ser humano, responsável pelo armazenamento de informações e de conhecimentos. Ela é a base para o desenvolvimento da linguagem, do reconhecimento das pessoas e dos objetos do cotidiano. Sem a memória, a cada dia, ou a cada momento, começaria uma vida nova, sem contar com o que foi aprendido anteriormente (MCGAUGH; IZQUIERDO 2000; BUDSON; PRIDE, 2001; IZQUIERDO, 2002; MARQUES, 2004; MOURÃO JÚNIOR; FARIA, 2015).

As memórias podem ser classificadas de acordo com diferentes critérios, entre eles, quanto a duração: imediata, curta duração ou de longa duração. As memórias de curta duração têm de poucos minutos até três ou quatro horas e as memórias de longa duração persistem por dias, meses ou anos. A diferença entre as memórias de curta e de longa duração reside não em seu conteúdo cognitivo, que é o mesmo, mas sim nos mecanismos subjacentes a cada uma delas. A formação de uma memória de longa duração envolve uma série de processos metabólicos no hipocampo e outras estruturas cerebrais. Enquanto esses processos não estiverem concluídos, as memórias de longa duração são lábeis. A memória ainda pode ser dividida 
em fases, como aquisição, consolidação e evocação (IZQUIERDO; MEDINA, 1997; ABEL; LATTAL, 2001; IZQUIERDO, 2002; BEAR et al., 2002; SQUIRE; KANDEL, 2003; QUILLFELDT, 2010).

Uma vez que o sistema colinérgico está envolvido na consolidação e recuperação de informações durante um novo aprendizado, o bloqueio dos receptores (entre eles os muscarínicos) de acetilcolina no sistema nervoso central induz déficit de memória temporário, afetando o desempenho em tarefas de memória (DEUTSCH, 1971; BARTUS et al., 1982; FLOOD; CHERKIN, 1986; GRASBY et al., 1995). A escopolamina (ESC) é um exemplo de antagonista não seletivo pós-sináptico dos receptores muscarínicos, utilizado como modelo experimental de déficit de memória (EBERT et al., 1998a; MCGAUGH, 1989; PRADO-ALCALÁ, 1993). Pelo fato da eliminação da ESC ser rápida, doses únicas têm apenas efeitos de curta duração (EBERT; $\mathrm{KIRCH}, 1998 b$ ).

Com base no exposto acima, o presente estudo investigou o efeito de uma única administração via oral do óleo essencial de RG sobre a aquisição de uma memória aversiva de curta e longa duração, sobre a evocação de uma memória espacial de longa duração, e ainda o efeito do óleo essencial de RG na reversão do déficit de memória induzido pela ESC em camundongos machos.

\section{Material e Métodos}

\section{Identificação e Coleta da Planta}

A planta foi coletada no distrito de Capoerê (longitude $27^{\circ} 45^{\prime} 00.17^{\prime}$ 'S e latitude $52^{\circ} 16^{\prime} 00.06$ 'O), próximo à cidade de Erechim, em agosto de 2011, e posteriormente identificada por Camila Ângela Zanella. No mesmo dia da coleta a planta foi armazenada em estufa de circulação de ar a $30{ }^{\circ} \mathrm{C}$ para secagem. Após cinco dias na estufa, a planta seca foi triturada em moinho de facas. Uma exsicata encontra-se registrada no Herbário Padre Balduíno Rambo (MURAU) da Universidade Regional Integrada do Alto Uruguai e das Missões, sob registro: HPBR 11.576. Foram utilizadas no estudo todas as partes do material vegetal, exceto as raízes.

\section{Obtenção do Óleo Essencial}

O óleo essencial foi extraído pelo método de hidrodestilação, conforme descrito por Mossi et al. (2011). Foram utilizadas $100 \mathrm{~g}$ de planta seca moída para dois litros de água destilada. Na hidrodestilação a planta seca é submersa na água e submetida a fervura em um sistema fechado. Os compostos voláteis são arrastados pelo aparelho graduado Clevenger e, após resfriamento, os compostos extraídos são coletados na forma de óleo essencial (SEFIDKON et al., 2007; AZIZ et al., 2018). Durante a extração, de aproximadamente $2 \mathrm{~h}$, foi obtido o rendimento total do óleo para cada 100 gramas de pó em $\mathrm{mL}$ $(\%$ p $/ v)$. Após a extração, o óleo essencial foi transferido para um recipiente de vidro do tipo âmbar e mantido a temperatura de $-20{ }^{\circ} \mathrm{C}$ para posterior utilização.

\section{Caracterização Química}

A caracterização química do óleo essencial foi realizada como descrito por Restello et al. (2009). Brevemente, as análises de composição química dos compostos voláteis e semivoláteis foram obtidas por Cromatografia Gasosa acoplada à Espectrometria de Massas GCMS (Shimadzu, Modelo QP 5050A). O gás hélio foi utilizado para arraste com vazão de 1,0 mL.min-1, detector de 1.2 Kv. A temperatura utilizada do injetor foi de $280^{\circ} \mathrm{C}$ e interface a $300^{\circ} \mathrm{C}$. A temperatura inicial de $60^{\circ} \mathrm{C}$ com tempo de corte do solvente em $5 \mathrm{~min}$ e aquecimento de $4,5^{\circ} \mathrm{C} /$ 
min até $280^{\circ} \mathrm{C}$. Foi empregada uma coluna capilar DB-5 (30 m x $0.25 \mathrm{~mm}$ de diâmetro $\mathrm{x} 0.25 \mu \mathrm{m}$ de espessura). O óleo essencial foi diluído em diclorometano na concentração de $50000 \mathrm{ppm}$. Os picos foram integrados no modo manual em porcentagem do composto. Para fins de identificação, foram comparados os espectros de massas das amostras com aproximadamente 170.000 compostos previamente identificados na biblioteca do equipamento (The Wiley Registry of Mass Spectral Data, 7 ed) (MOSSI et al., 2010).

\section{Animais}

O presente estudo foi aprovado pelo Comitê de Ética em Pesquisa da Universidade Regional Integrada - URI Erechim, RS (registro 184/TCA/11). Foram usados camundongos Swiss adultos machos, com 45 dias, pesando $35 \pm 5 \mathrm{~g}$, obtidos do Laboratório de Experimentação Animal da URI Erechim. Os camundongos foram mantidos em caixas plásticas, quatro a cinco por caixa, em ambiente com temperatura controlada $(22 \pm 2$ ${ }^{\circ} \mathrm{C}$ ), em um ciclo de $12 \mathrm{~h}$ claro/escuro, com livre acesso a ração e água. Todos os experimentos foram conduzidos entre $13 \mathrm{~h}$ e $18 \mathrm{~h}$ e seguiram os princípios éticos da Sociedade Brasileira de Animais de Laboratório. Os camundongos foram escolhidos randomicamente para compor os grupos experimentais e grupos independentes foram utilizados para cada protocolo experimental.

\section{Delineamento Experimental}

Para a realização das tarefas comportamentais, os camundongos foram divididos em quatro grupos experimentais. Controle (veículo + veículo), RG (óleo essencial de $\mathrm{RG}-100 \mathrm{mg} / \mathrm{kg}+$ veículo), ESC (veículo + ESC $3 \mathrm{mg} / \mathrm{kg}$ ) e o grupo RG + ESC (de óleo essencial de RG - $100 \mathrm{mg} / \mathrm{kg}+\mathrm{ESC}$ $3 \mathrm{mg} / \mathrm{kg}$ ). Todos os grupos receberam, pri- meiramente, uma única administração via oral (sonda intragástrica, volume máximo de $0,6 \mathrm{~mL}$ ) de veículo (óleo de canola obtido comercialmente da marca SALADA $\AA$ com acidez máxima de $0,2 \%$ de acordo com o fabricante) ou de óleo essencial de RG. E uma única administração intraperitoneal (volume máximo de $0,4 \mathrm{~mL}$ ) de ESC ou veículo (solução salina $0,9 \%$ ). Para as doses escolhidas, foram utilizados trabalhos prévios da literatura (BORES et al., 1996; LIMA et al., 2009; DA SILVA et al., 2009). A dose do óleo essencial de RG foi obtida considerando o óleo essencial após a extração como $100 \%$. A ESC (Scopolamine hydrochloride $\geq 90 \%$ ) foi obtida comercialmente da empresa Sigma (número de catálogo: S1013), São Paulo, SP, Brasil.

A administração única do óleo essencial de RG foi realizada 45 minutos antes das tarefas comportamentais e a ESC $30 \mathrm{~min}$ antes das tarefas comportamentais. A administração foi delineada para acessar a aquisição e a evocação (diferentes fases da memória). $\mathrm{O}$ teste de campo aberto foi utilizado para verificar a atividade locomotora e exploratória dos camundongos sob efeito dos tratamentos avaliados. No teste da esquiva inibitória, a administração 45 minutos antes da sessão-treino foi escolhida para verificar se o óleo essencial de RG modularia o processo de aquisição de uma memória aversiva, sendo a consequência dessa única administração avaliada separadamente para a aquisição de uma memória de curta e de longa duração. Já para a tarefa de MWM, a administração feita 45 minutos antes da sessão-teste foi escolhida para verificar se o óleo essencial de RG modularia o processo de evocação de uma memória espacial de longa duração. As avaliações comportamentais foram feitas por um observador que desconhecia o tratamento dos camundongos. E, antes de colocar um novo camundongo nos aparatos experimentais, estes eram limpos com álcool 10\%. 


\section{Testes Comportamentais}

\section{Campo Aberto}

Essa tarefa foi realizada em um aparato experimental quadrado, confeccionado em madeira com $30 \mathrm{~cm}$ de largura, $30 \mathrm{~cm}$ de comprimento e $15 \mathrm{~cm}$ de altura, o chão contendo quadrantes para facilitar a avaliação dos comportamentos. Os camundongos eram colocados no aparato por 3 minutos com exploração livre. Foram contados o número de cruzamentos (crossings, quando o camundongo cruza os quadrantes definidos no chão do aparato experimental) e levantamentos (rearings, quando o camundongo levanta as duas patas da frente) (ARCHER, 1973). Foram efetuadas duas sessões: uma sessão de treino, logo após as administrações; e uma sessão-teste, 24 horas após a sessão-treino. A tendência natural do animal em um ambiente novo é a de explorá-lo, apesar do conflito com o medo provocado pelo novo ambiente (MONTGOMERY, 1955).

\section{Esquiva Inibitória}

Esta tarefa foi realizada em uma caixa de condicionamento, com a parte frontal de vidro. Na extremidade esquerda da caixa foi colocada uma plataforma de madeira de $8 \mathrm{~cm}$ de largura e $25 \mathrm{~cm}$ de comprimento, situada a $5 \mathrm{~cm}$ do chão da caixa. O chão da caixa é formado por uma grade de barras de inox, as quais apresentam $0,2 \mathrm{~cm}$ de diâmetro e encontram-se separadas umas das outras por um espaço de $1 \mathrm{~cm}$.

$\mathrm{Na}$ sessão-treino os camundongos foram colocados na plataforma e, ao descer com as quatro patas nas grades de inox, receberam um choque elétrico de $0,4 \mathrm{~mA}$, durante 2 segundos. O tempo para latência de descida foi registrado. Logo após, os camundongos foram retirados do equipamento e colocados em suas caixas de origem (MARQUES, 2004; ZANELLA et al., 2012).

Nas sessões-teste (90 minutos para memória de curta duração e 24 horas para memória de longa duração), os camundongos foram reexpostos à caixa de condicionamento, mas com a extinção do choque elétrico. Foi estabelecido um teto máximo de latência de descida da plataforma correspondente a 60 segundos na sessão-treino e 180 segundos na sessão-teste, igualmente para todos os grupos (ROESLER et al., 2003), de modo que as latências superiores a estes padrões foram consideradas como tais. O aumento do tempo de descida da plataforma na sessão-teste é interpretado como formação da memória aversiva, uma vez que o animal evita descer da plataforma relembrando o estímulo aversivo (choque) recebido na experiência prévia (IZQUIERDO, 2002).

\section{Labirinto Aquático de Morris}

Para esta tarefa foi utilizado um tanque (1 $\mathrm{m}$ de diâmetro), dividido em quadrantes (norte, sul, leste e oeste), contendo água no seu interior em uma profundidade de $30 \mathrm{~cm}$. Durante o treinamento, foi colocada uma plataforma (10 cm de diâmetro) obscurecida com o preto e submersa a $1 \mathrm{~cm}$ abaixo da superfície de água $\left(21 \pm 2^{\circ} \mathrm{C}\right)$, sempre dentro do mesmo quadrante.

Cada treino consistiu de um bloco de quatro tentativas, nos quais os camundongos eram colocados em cada um dos quadrantes, e liberados para nadar por no máximo um minuto cada treino. O treinamento dos camundongos ocorreu durante quatro dias consecutivos, antecedendo as administrações. Se não encontrassem a plataforma em 60 segundos, os camundongos eram guiados até a plataforma, e mantidos sobre ela por 10 segundos. Entre cada treino, os camundongos eram colocados em uma caixa para descansar por 20 segundos. Para este teste foi registrado 
o tempo que o animal levou para alcançar a plataforma durante os quatro dias de treino, para possibilitar a construção de uma curva de aprendizagem.

Nas paredes da sala de experimentação foram colocadas quatro pistas visuais. As pistas continham $45 \mathrm{~cm} \mathrm{x} 45 \mathrm{~cm}$ e foram posicionadas $30 \mathrm{~cm}$ acima da borda superior do tanque e os símbolos estavam posicionados exatamente no ponto médio de cada quadrante. No quadrante norte foi colocado um círculo, no quadrante sul um triângulo, no quadrante leste um quadrado e no quadrante oeste uma cruz. No quinto dia, os camundongos receberam as administrações conforme o protocolo descrito anteriormente e a plataforma foi retirada do tanque para o teste ser realizado. $\mathrm{O}$ teste consistiu em colocar os camundongos na posição do tanque no quadrante oposto ao qual estava a plataforma, permitindo avaliar a memória espacial e compará-la entre os diversos grupos (MORRIS, 1984; PREDIGER et al., 2008).

Durante a sessão de teste de cada animal, o tempo despendido no quadrante correto e o tempo que cada camundongo despendeu para achar a plataforma (representando o local onde ela estava posicionada) foram analisados. $\mathrm{O}$ registro do desempenho dos camundongos foi feito por meio de uma câmera para filmagem colocada sobre o tanque e, posteriormente, os dados foram analisados em um computador.

\section{Ensaio para determinação da AChE in vitro e ex vivo}

Para o ensaio in vitro, o óleo essencial de RG foi diluído em $53 \%$ etanol e analisado em uma curva de concentração de 1,10 , 100,500 e $1000 \mu \mathrm{g} / \mathrm{mL}$. Para o ensaio ex vivo, foi utilizado como substrato da reação o córtex pré-frontal, hipocampo e estriado dos camundongos que passaram pelas tarefas comportamentais (exceto da tarefa campo aberto). Ambos os ensaios foram realizados de acordo com Ceschi et al. (2016). A atividade da $\mathrm{AChE}$ foi medida pelo método de Ellman et al. (1961). A concentração de proteína foi medida pelo método de Lowry modificado (PETERSON, 1977), usando albumina bovina como padrão. Foram utilizados 5 camundongos por concentração, e as atividades foram medidas em triplicata.

\section{Análise dos Dados}

Os dados obtidos foram analisados quanto à distribuição pelo teste de KolmogorovSmirnov e, por apresentarem distribuição normal, foram submetidos a uma Análise de Variância (ANOVA) de vias repetidas, seguida pelo teste post-hoc de Newman-Keuls.

Para a análise estatística dos valores obtidos para a atividade da AChE entre os diferentes grupos, foi aplicado uma ANOVA de uma via, seguido do teste post-hoc de Tukey. Todos os resultados são expressos por média e erro padrão da média. O nível aceitável de significância foi de $\mathrm{p} \leq 0,05$ e todas as análises foram feitas com auxílio do software Statistica 8 e os gráficos com o software GraphPad 5.

\section{Resultados}

\section{Análise da Composição Química do Óleo Essencial}

$\mathrm{O}$ rendimento do óleo essencial obtido para $100 \mathrm{~g}$ de planta moída foi de $0,8 \mathrm{~mL}$ $(\mathrm{p} / \mathrm{v})$. O cromatograma do óleo essencial de RG apresentou 6 picos. Os respectivos compostos estão representados na Tabela I. Dois compostos mostraram-se majoritários: 2-nonanone $(37,91 \%), 2$-undecanone $(34,71 \%)$ (Tabela I). 
Tabela I - Compostos químicos identificados pela análise cromatográfica

\begin{tabular}{cccc}
\hline Pico & Tempo de Retenção & Área \% & Composto \\
\hline 1 & 6,100 & 37,91 & 2-nonanone \\
2 & 7,500 & 0,54 & geireno \\
3 & 11,233 & 0,67 & 2-decanone \\
4 & 13,600 & 2,79 & 2-octanol-acetato \\
5 & 15,075 & 0,93 & geireno \\
6 & 16,875 & 34,71 & 2-undecacone \\
\hline
\end{tabular}

\section{Avaliações Comportamentais}

Uma única administração do óleo essencial de RG não alterou o número de cruzamentos, nem o número de levantamentos no teste de campo aberto, quando comparado com o grupo-controle (Figura 1). Entretanto, os camundongos que receberam ESC aumentaram significativamente o número de levantamentos (Figura 1B) na sessão de teste (24h após a administração). O óleo essencial de $R G$ não foi capaz de prevenir esse efeito (ANOVA de vias repetidas $\mathrm{F}(1,20)=18,270$, $\mathrm{p}=0,00037)$.

Com relação à memória de curta duração, avaliada na tarefa de esquiva inibitória, foi possível observar que, no protocolo utilizado pelo presente estudo, o grupo-controle aumentou significativamente a latência para descida da plataforma na sessão de teste (90 min depois da sessão-treino) (ANOVA de medidas repetidas $\mathrm{F}(1,30)=5,2154$, $\mathrm{p}=0,02964)$. A ESC foi capaz de abolir a aquisição da memória de curta duração, uma vez que não existem diferença entre a sessão-treino e teste (Figura 2A).

Diferente do esperado, o grupo que recebeu o óleo essencial de RG passou menos tempo na plataforma na sessão-teste; o mesmo aconteceu no grupo que recebeu ambos os óleos, essencial de RG e ESC, sugerindo que o óleo essencial interferiu com a aquisição de uma memória de curta duração e que não foi capaz de reverter o dano causado pela ESC (Figura 2A).

Figura 1 - Efeitos da administração aguda do óleo essencial de Ruta graveolens $L$. no teste de campo aberto em camundongos machos. A. Número de cruzamentos. B. Número de levantamentos. Os resultados são expressos em média + erro padrão ( $\mathrm{n}=5-6$ camundongos por grupo). ANOVA de medidas repetidas, post-hoc Newmann Keuls * $\mathrm{p} \leq 0,05$; ** $\mathrm{p} \leq 0,001$. RG: óleo essencial de Ruta graveolens L. (100 $\mathrm{mg} / \mathrm{kg}$ ); Esc: escopolamina (3 mg/kg). Ns: não significativo.

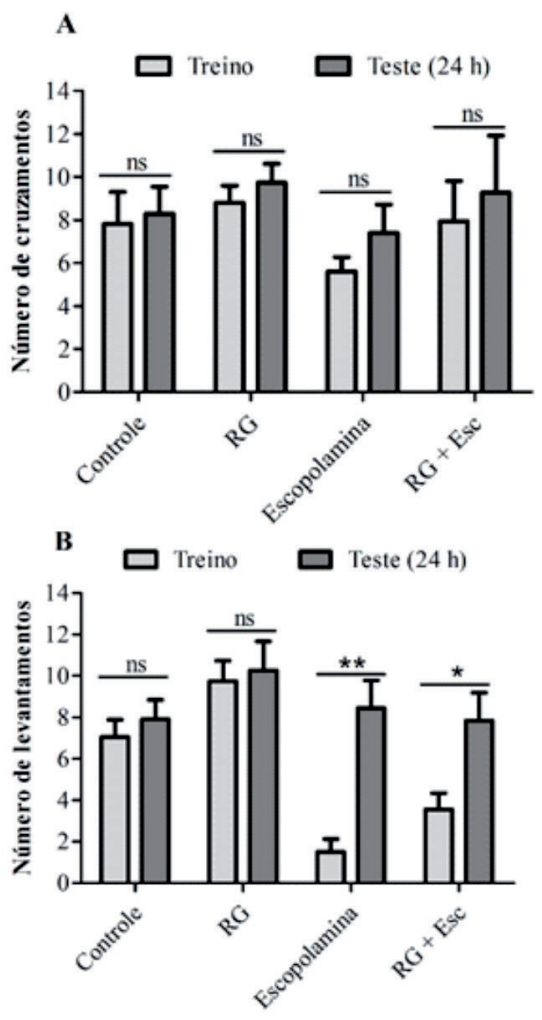


Figura 2 - Efeitos da administração aguda do óleo essencial de Ruta graveolens $L$. sobre a memória de curta e longa duração na tarefa de esquiva inibitória em camundongos machos. A. Memória de curta duração $(90 \mathrm{~min})$. B. Memória de longa duração (24h). Os resultados são expressos em média + erro padrão ( $\mathrm{n}=8-10$ camundongos por grupo). ANOVA de medidas repetidas, post-hoc Newmann Keuls * $\mathrm{p} \leq 0,05$ diferença significativa comparando-se sessão-treino e teste. $\# \mathrm{p} \leq 0,05$ em A. diferença significativa comparando-se com a sessão-teste do grupo-controle. \# $\mathrm{p} \leq 0,05 \mathrm{em} \mathbf{B}$. diferença significativa comparando-se com a sessão-teste do grupo RG. RG: óleo essencial de Ruta graveolens L. (100 mg/kg). Esc: escopolamina $(3 \mathrm{mg} / \mathrm{kg})$. Ns: não significativo.
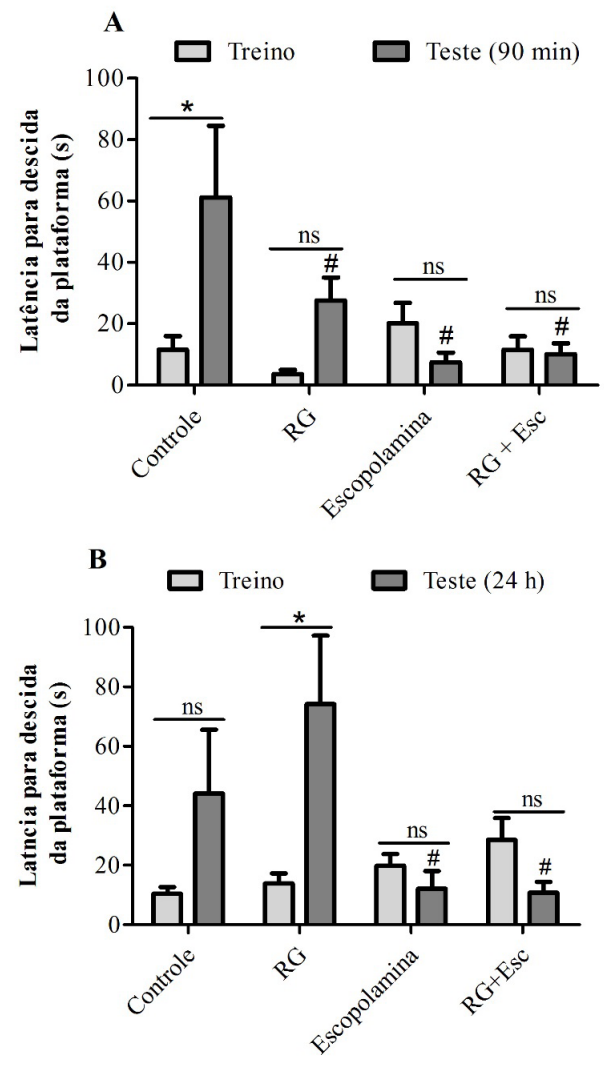

Com relação à memória de longa duração, o grupo-controle, nesse protocolo, não aumentou significativamente o tempo de permanência na plataforma durante a sessão-teste. Por outro lado, os camundongos que receberam o óleo essencial de RG aumentaram significativamente a latência de descida da plataforma (ANOVA de medidas repetidas $\mathrm{F}(1,31)=12,188, \mathrm{p}=0,00147)$. Esse resultado sugere que o óleo essencial de RG melhorou a aquisição de uma memória de longa duração. Apesar de promover essa melhora cognitiva, o óleo essencial de RG, na dose utilizada, não foi capaz de prevenir o déficit causado pela ESC (Figura 2B).

No MWM, o tempo despendido pelos camundongos para encontrar a plataforma submersa é mostrado na Figura 3. Não foram encontradas diferenças entre os tratamentos no parâmetro latência para plataforma. Também não foram observadas diferenças signficativas entre os grupos com relação ao parâmetro tempo gasto no quadrante correto (dados não mostrados).

$\mathrm{Na}$ análise in vitro, a concentração de $1000 \mu \mathrm{g} / \mathrm{ml}$ do óleo essencial de RG foi capaz de inibir 33,7 $\pm 6,7 \%$ da AChE (ANOVA de uma via, post-hoc de Tukey $\mathrm{F}(5,24)=3,289$, $\mathrm{p}=0,0211$ ) (Figura 4). Na análise ex vivo das estruturas córtex pré-frontal, hipocampo e estriado, não foram encontradas diferenças significativas de inibição da enzima $\mathrm{AChE}$ em nenhum dos tratamentos em nenhuma das tarefas comportamentais empregadas no presente estudo. O veículo (óleo de canola) utilizado para diluir o óleo essencial de RG nos experimentos in vivo não causou per se uma inibição da $\mathrm{AChE}$ (dados não mostrados). 
Figura 3 - Curva de aprendizado e os efeitos da administração aguda do óleo essencial de Ruta graveolens L. na evocação da memória espacial no labirinto aquático de Morris. O gráfico mostra as latências para encontrar a plataforma(s) observadas ao longo dos quatro dias de treinamento. A seta indica que os tratamentos foram realizados na fase de evocação da memória espacial, antes da sessão-teste (quinto dia). Os resultados são expressos em média \pm erro padrão ( $\mathrm{n}=8-10$ camundongos por grupo). Não foram encontradas diferenças significativas entre os grupos. RG: óleo essencial de Ruta graveolens L. (100 mg/kg). Esc: escopolamina $(3 \mathrm{mg} / \mathrm{kg})$.

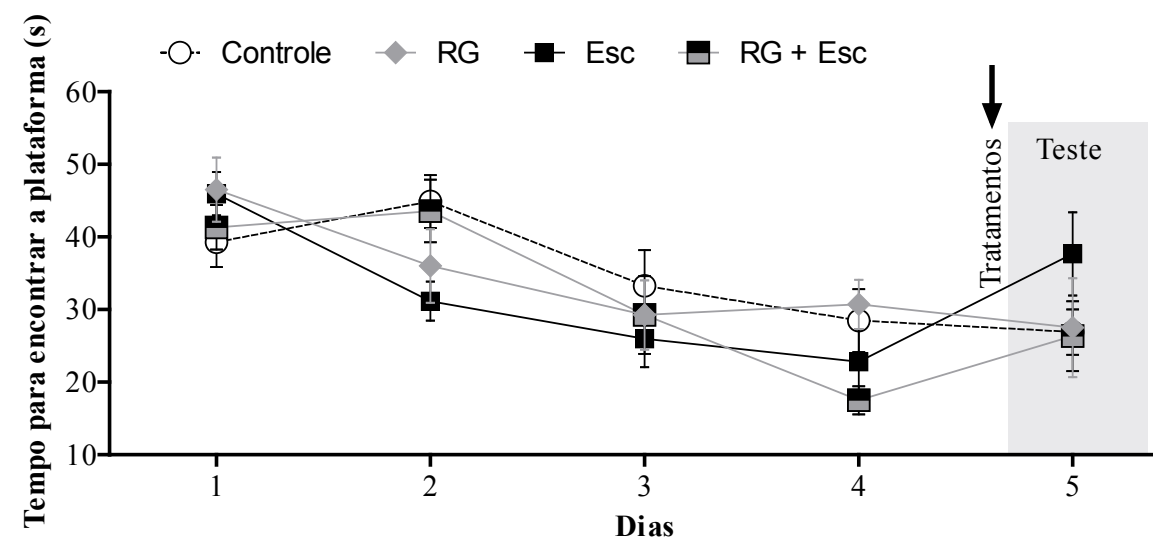

Figura 4 - Efeitos in vitro do óleo essencial de Ruta graveolens $L$. sobre a atividade da enzima acetilcolinesterase. Os resultados são expressos em média + erro padrão da porcentagem de atividade da acetilcolinesterase $(\mathrm{n}=5)$. ANOVA de uma via post-hoc de Tukey. ${ }^{* *} \mathrm{p}<0,01$ diferença significativa comparando-se com o grupo-controle. RG: óleo essencial de Ruta graveolens L. (concentrações indicadas no gráfico). AChE: Acetilcolinesterase.

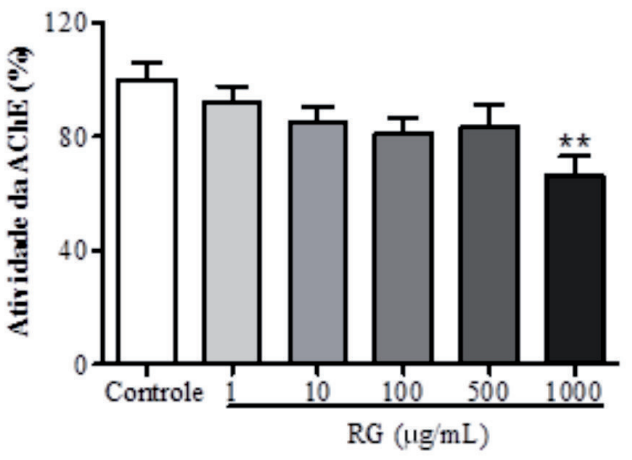

\section{Discussão}

Um grande número de plantas medicinais vem sendo usado em todo o mundo pela medicina tradicional. Na literatura, diferentes compostos de produtos naturais têm sido avaliados como fontes promissoras para o desenvolvimento de possíveis medicamentos (BARBOSA FILHO et al., 2006). Cerca de $74 \%$ dos compostos puros naturais empregados na indústria farmacêutica foram isolados seguindo recomendações da medicina popular (SILVA JÚNIOR, 1996). O Ginkgo biloba é um exemplo de fitoterápico com possíveis propriedades neuroprotetoras que tem seus efeitos amplamente estudados e discutidos (GOLD et al., 2002; TAN et al., 2015).

No presente estudo, foram encontrados dois compostos majoritários no óleo essencial de RG - 2-nonanone (37,91\%) e 2-undecanone $(34,71 \%)$ - extraídos pelo processo de hidrodestilação com auxílio de aparelho Clevenger. Stashenko et al., (2000) observaram a presença de 2 -nonanone $(8,9 \%)$ e 2 -undecanone $(13,4 \%)$, dentre outros compostos. A diferença nas concentrações obtidas possivelmente está relacionada com o diferente método de extração utilizado pelos autores (extração com $\mathrm{CO}_{2}$ subcrítico com auxílio de aparelho Soxhlet) (STASHENKO et al., 2000). Yaacob et al. (1989) também observaram que 2 -undecanone $(30,73 \%)$ e 2 -nonanone $(18,06 \%)$ são compostos pre- 
sentes de forma majoritária no óleo essencial de RG. Os resultados obtidos por De Feo et al. (2002) também demonstraram a presença majoritária de 2 -undecanone $(46,8 \%)$ e 2-nonanone (18,8\%). Apesar de diferentes trabalhos avaliarem a composição química do óleo essencial de RG, não foram encontrados, até o presente momento, trabalhos que investiguem os efeitos desses compostos isolados sobre a memória de curta e longa duração em camundongos, ressaltando a necessidade de trabalhos nessa área.

Das avaliações comportamentais empregadas no presente estudo, sabe-se que o teste de campo aberto é caracterizado como uma tarefa não aversiva. $\mathrm{O}$ comportamento de levantar representa uma postura exploratória inata de pequenos roedores e, quanto mais novo o ambiente, mais vezes o animal tende a exibir tal comportamento. $\mathrm{O}$ número de cruzamentos também expressa exploração e alterações na atividade locomotora (QUILLFELDT, 2010).

Os camundongos que receberam ESC no presente estudo aumentaram significativamente o número de levantamentos na sessão de teste do campo aberto. $\mathrm{O}$ aumento no número de levantamentos acontece normalmente quando o animal é exposto a um ambiente novo. Uma vez que, na primeira exposição ao aparato experimental, os camundongos estavam sobre os efeitos da ESC, o aumento significativo no número de levantamentos na sessão-teste sugere que os camundongos não se lembram da exposição prévia. Por outro lado, o óleo essencial de RG não alterou a exploração nem a atividade locomotora, mas também não foi capaz de prevenir o prejuízo causado pela ESC. Não foram observadas alterações no número de cruzamentos, o que sugere que a atividade locomotora desses animais não foi alterada pelos tratamentos utilizados no presente estudo.

Com relação à memória de curta duração na tarefa de esquiva inibitória, o óleo essen- cial de RG não foi capaz de potencializar essa memória, nem foi capaz de prevenir os déficits induzidos pela ESC. Entretanto, para a memória de longa duração, o óleo essencial de $R G$ foi capaz de potencializar a aquisição dessa memória. Nesse sentido, a nossa hipótese de que o óleo essencial de RG poderia inibir a $\mathrm{AChE}$ e, por esse motivo, recuperar os déficits de memória induzidos pela ESC, e ainda facilitar a aquisição de uma memória de curta duração, foi refutada. Contudo, a nossa hipótese de que o óleo essencial de RG poderia facilitar a aquisição de uma memória de longa duração foi confirmada. Não existem estudos sobre o mecanismo de ação do óleo essencial de RG que permitam uma discussão relacionada aos possíveis alvos celulares que promoveram tal efeito. $\mathrm{Na}$ literatura é possível encontrar exemplos de outros compostos capazes de prevenir o dano causado pela escopolamina na tarefa de esquiva inibitória. Um desses exemplos é a cafeína, presente no café, uma das bebidas mais consumidas no mundo (BOTTON et al., 2010; NIEBER, 2017).

A tarefa de MWM é considerada por alguns autores um paradigma complexo, em que o desempenho dos camundongos é influenciado por fatores relacionados a atenção e motivação, bem como pela função sensório-motoras, e estes fatores coletivamente podem determinar o sucesso ou o fracasso em encontrar a plataforma (MORRIS, 1984; PREDIGER et al., 2008). Diferente do esperado, ao se utilizar a concentração de ESC de $3 \mathrm{mg} / \mathrm{kg}$, não foram observados déficits cognitivos com relação ao parâmetro de latência para plataforma na sessão de teste da tarefa de MWM. Apesar de não ter sido eficaz nessas condições experimentais (no sentido de prejudicar a evocação de uma memória espacial de longa duração), a ESC causou déficit cognitivo nas outras tarefas comportamentais empregadas. Nessa tarefa o óleo essencial de RG per se não promoveu nenhum efeito. 
No presente estudo não foi observada inibição da enzima acetilcolinesterase nos ensaios ex vivo, o que corrobora a não reversão do dano causado pela ESC observado na tarefa de esquiva inibitória e campo aberto. Em contrapartida, o óleo essencial de RG mostrou-se eficaz em aumentar o potencial cognitivo, no sentido de facilitar a aquisição da memória de longa duração na tarefa de esquiva inibitória, por um mecanismo de ação ainda desconhecido.

Adsersen et al. (2006) observaram que o extrato aquoso de RG na concentração de $0,1 \mathrm{mg} / \mathrm{mL}$ inibiu $22 \%$ da AChE, já o extrato metanólico na mesma concentração inibiu $39 \%$ da AChE in vitro. No presente estudo, foi observado que para inibir 33,7 $\pm 6,7 \%$ da AChE foi necessária uma concentração de óleo essencial 10 vezes maior $(1 \mathrm{mg} / \mathrm{mL})$ do que a utilizada de extrato metanólico no estudo de Adsersen et al. (2006). Pelo fato de o extrato metanólico apresentar uma taxa de inibição da $\mathrm{AChE}$ mais alta em concentrações menores, o efeito do extrato metanólico de $\mathrm{RG}$ na memória e na amnésia induzida pela escopolamina seria interessante de ser investigado em estudos futuros.

Alguns óleos essenciais, de outras plantas medicinais, mesmo em concentrações menores, promovem uma inibição da $\mathrm{AChE}$ mais elevada. Apenas para citar alguns exemplos, o óleo essencial de Citrus auranlifolia, na concentração de $0,1 \mu \mathrm{l} / \mathrm{ml}$, inibiu $65,8 \pm$ $3,55 \%$ da AChE e o óleo essencial de Salvia officinalis, na concentração de $0,1 \mu 1 / \mathrm{ml}$, apresentou uma inibição de 52,4 $\pm 0,8 \%$ (PERRY et al., 1996).

É importante ressaltar que a inibição da AChE é apenas um dos mecanismos envolvidos com a facilitação de memórias. Por exemplo, alguns estudos sugerem que a planta Rosmarinus officinalis pode facilitar a memória em roedores e até mesmo em humanos (MOSS et al., 2003; ZANELLA et al., 2012; NEMATOLAHI et al., 2018;
BENNY; THOMAS, 2019), porém apresenta uma pequena porcentagem de inibição sobre a AChE, em torno de 17\% (PERRY et al., 1996; ADSERSEN et al., 2006).

O nosso estudo responde algumas perguntas, porém muitas ainda precisam ser respondidas. Seria interessante, em estudos futuros, investigar a biodisponibilidade do óleo essencial de RG, pois, para determinar se um composto fornece neuroproteção após exposição dietética, é fundamental entender como estes compostos são absorvidos, onde são metabolizados e quais são os metabólitos biologicamente ativos ou inativos gerados. Muitos compostos são fracamente absorvidos a partir do intestino e são altamente metabolizados, ou rapidamente eliminados. Portanto, a manutenção de uma concentração elevada no plasma requer a ingestão repetida (SCALBERT; WILLIAMSON, 2000). Por esse motivo, um tratamento crônico utilizando o óleo essencial de RG acrescentaria resultados promissores à literatura da área. Seria interessante, também, avaliar os compostos separadamente, concomitante com o uso de diferentes antagonistas para buscar entender os mecanismos de ação do óleo essencial de RG.

\section{Considerações Finais}

No presente estudo foi demonstrado, pela primeira vez, que uma única administração do óleo essencial de RG (100 mg/kg) facilitou a aquisição de uma memória de longa duração. Entretanto, uma única administração não foi capaz de reverter a amnésia induzida pela ESC. Os achados comportamentais corroboram os resultados ex vivo, em que não houve inibição significativa do óleo essencial de RG sobre a atividade da AChE nas estruturas hipocampo, córtex pré-frontal e estriado. A perda de memória é um dos sintomas presentes em muitas condições 
neurodegenerativas e afeta muito a qualidade de vida dos pacientes (SANDRY, 2015). Por esse motivo, a busca por novos compostos dentro da pesquisa básica é uma fonte importante de conhecimento. Em longo prazo, o estudo de cada composto descoberto pode ser aprofundado para que, no futuro, sejam produzidos medicamentos eficazes para prevenir ou recuperar déficits cognitivos.

\section{AGRADECIMENTOS}

Os autores agradecem o financiamento concedido para a realização desse projeto às bolsas PIIC-URI de iniciação científica, à CAPES e ao CNPq.

Abreviações: AChE: Acetilcolinesterase; MWM: Labirinto Aquático de Morris; RG: Ruta graveolens $L$.

\section{REFERÊNCIAS}

ABEL, T.; LATTAL, K. M. Molecular mechanisms of memory acquisition, consolidation and retrieval. Current Opinion in Neurobiology, v. 11, n. 2, p. 180-187, 2001. Disponível em: https:// pubmed.ncbi.nlm.nih.gov/11301237. Acesso em: 19 fev. 2020.

ADSERSEN, A.; GAUGUIN, B.; GUDIKSEN, L.; JÄGER, A. K. Screening of plants used in Danish folk medicine to treat memory dysfunction for acetylcholinesterase inhibitory activity. Journal of Ethnopharmacology, v. 104, n. 3, p. 418-422, 2006. Disponível em: https://pubmed. ncbi.nlm.nih.gov/16280217. Acesso em: 19 fev. 2020.

AGATONOVIC-KUSTRIN, S.; KUSTRIN, E.; MORTON, D. W. Essential oils and functional herbs for healthy aging. Neural Regeneration Research, v. 14, n. 3, p. 441-445, 2019.

ARCHER, J. Tests for emotionality in rats and mice: a review. Animal Behavior, v. 21, n. 2, p. 205235, 1973. Disponível em: https://pubmed.ncbi.nlm.nih.gov/4578750. Acesso em: 19 fev. 2020.

ARONSON, J. K.; FERNER, R. E.; HUGHES, D. A. Defining rewardable innovation in drug therapy. Nature Reviews Drug Discovery, v. 11, p. 253-254, 2012. Disponível em: https://pubmed. ncbi.nlm.nih.gov/22460109. Acesso em: 19 fev. 2020.

AZIZ, Z. A. A.; AHMAD, A.; SETAPAR, S. H. M.; KARAKUCUK, A.; AZIM, M. M.; LOKHAT, D.; RAFATULLAH, M.; GANASH, M.; KAMAL, M. A.; ASHRAF, G. M. D. Essential oils: extraction techniques, pharmaceutical and therapeutic potential - A Review. Current Drug Metabolism, v. 19, n. 13, p. 1100-1110, 2018. Disponível em: https://pubmed.ncbi.nlm.nih. gov/30039757. Acesso em: 19 fev. 2020.

BARBOSA FILHO, J. M.; MEDEIROS, K. C. P.; DINIZ, M. F. F. M.; BATISTA, L. M.; ATHAYDE FILHO, P. F.; SILVA, M. S.; CUNHA, E. V. L.; ALMEIDA, J. R. G. S.; QUINTANS JÚNIOR, L. J. Natural products inhibitors of the enzyme acetylcholinesterase. Revista Brasileira de Farmacognosia, v. 16, n. 2, p. 258-285, 2006. Disponível em: http://www.scielo.br/scielo. php?script=sci_arttext\&pid=S0102-695X2006000200021. Acesso em: 19 fev. 2020.

BARTUS, R.T.; DEAN, R.L.; BEER, B.; LIPPA, A. S. The cholinergic hypothesis of geriatric memory dysfunction. Science, v. 217, n. 4558, 1982. Disponível em: https://pubmed.ncbi.nlm.nih. gov/7046051. Acesso em: 19 fev. 2020. 
BEAR, M. F.; CONNORS, B. W.; PARADISO, E. M.; Neurociências: desvendando o sistema nervoso. 3. ed. Porto Alegre/RS: Artmed, 2002.

BENNY, A.; THOMAS, J. Essential oils as treatment strategy for alzheimer's disease: current and future perspectives. Planta Medica, v. 85, n. 3, p. 239-248, 2019. Disponível em: https://pubmed. ncbi.nlm.nih.gov/30360002. Acesso em: 19 fev. 2020.

BORES, G. M.; HUGER, F. P.; PETKO, W.; MUTLIB, A. E.; CAMACHO, F.; RUSH, D. K.; SELK,D.E.; WOLF, V.; KOSLEY, R. W.; DAVIS, L.; VARGAS, H. M.; Pharmacological evaluation of novel Alzheimer's disease therapeutics: acetylcholinesterase inhibitors related to galanthamine.

Journal of Pharmacology and Experimental Therapeutics, v. 277, p. 728-738, 1996. Disponível em: https://pubmed.ncbi.nlm.nih.gov/8627552. Acesso em: 21 fev. 2020.

BOTTON, P. H.; COSTA, M. S.; ARDAIS, A. P.; MIORANZZA, S.; SOUZA, D.O.; ROCHA, J. B. T.; PORCIÚNCULA, L. O. Caffeine prevents disruption of memory consolidation in the inhibitory avoidance and novel object recognition tasks by scopolamine in adult mice. Behavioural Brain Research, v. 214, p. 254-259, 2010. Disponível em: https://pubmed.ncbi.nlm.nih.gov/20553765. Acesso em 21 fev. 2020.

BOWEN, D. M.; SPILLANE, J. A.; CURZON, G.; MEIER-RUGE, W.; WHITE, P.; IWANGOFF, P.; DAVISON, A. N. Accelerated aging or selective neuronal loss as an important cause of dementia. Lancet, v. 313, p. 11-14, 1979. Disponível em: https://pubmed.ncbi.nlm.nih.gov/83462. Acesso em: 21 fev. 2020.

BRISKIN, D. P. Medical plants and phytomedicines. Linking plant biochemistry and physiology to human health. Plant Physiology, v. 124, n. 2, p. 507-514, 2000. Disponível em: https://pubmed.ncbi. nlm.nih.gov/11027701. Acesso em: 22 fev. 2020.

BUDSON, A. E.; PRICE, B. H. Memory: Clinical disorders. Encyclopedia of life sciences Nature Publishing Group, p. 1-8, 2001. Disponível em: http://www.ufrgs.br/ppgneuro/artigos/ MMRdisorders_ELS2003.pdf. Acesso em: 22 fev. 2020.

CESCHI, M. A.; COSTA, J. S.; LOPES, J. P. B.; CAMARA, V. S.; CAMPO, L. F.; BORGES, A. C. A.; GONÇALVES, C. A. S.; SOUZA, D. F.; KONRATH, E. L; KARL, A. L. M.; GUEDES, I. A.; DARDENNE, L. E. Novel series of tacrine-tianeptine hybrids: Synthesis, cholinesterase inhibitory activity, S100B secretion and a molecular modeling approach. European Journal of Medicinal Chemistry, v. 121, p. 758-772, 2016. Disponível em: https://pubmed.ncbi.nlm.nih.gov/27392529. Acesso em: 22 fev. 2020.

CHIU, K. W.; FUNG, A. Y. The cardiovascular effects of green beans (Phaseolus aureus), common rue (Ruta graveolens), and kelp (Laminaria japonica) in rats. General Pharmacology, v. 29, n. 5, p. 859-862, 1997. Disponível em: https://pubmed.ncbi.nlm.nih.gov/9347338. Acesso em: 22 fev. 2020.

DA SILVA, A. L.; SILVA MARTINS, B. D.; LINCK V. D. M.; HERRMANN, A. P.; MAI, N.; NUNES, D. S.; ELISABETSKY, E. MK801- and scopolamine-induced amnesias are reversed by an Amazonian herbal locally used as a "brain tonic". Psychopharmacology (Berl), v. 202, n. 1-3, p. 165-172, 2009. Disponível em: https://pubmed.ncbi.nlm.nih.gov/18695930. Acesso em: 22 fev. 2020.

DA SILVA, R. H.; JÚNIOR W. S. F.; DE MEDEIROS P. M.; ALBUQUERQUE, U. P. Adaptive memory and evolution of the human naturalistic mind: Insights from the use of medicinal plants. PLoS One, v. 14, n. 3, p. e0214300, 2019. Disponível em: https://pubmed.ncbi.nlm.nih. gov/30913230. Acesso em: 22 fev. 2020.

DEUTSCH, J. A. The cholinergic synapse and the site of memory. Science, v.174, n. 4011, 1971. Disponível em: https://pubmed.ncbi.nlm.nih.gov/4330469. Acesso em: 22 fev.2020.

DE FEO, V.; DE SIMONE, F.; SENATORE, F. Potential allelochemicals from the essential oil of Ruta graveolens. Phytochemistry, v. 61, n. 5, p. 573-578, 2002. Disponível em: https://pubmed. ncbi.nlm.nih.gov/12409025. Acesso em: 24 fev. 2020. 
EBERT, U.; KIRCH, W. Scopolamine model of dementia: electroencephalogram findings and cognitive performance. European Journal of Clinical Investigation, v. 28, n. 11, p. 944-949, 1998b. Disponível em: https://pubmed.ncbi.nlm.nih.gov/9824440. Acesso em: 22 fev. 2020.

EBERT, U.; OERTEL, R.; WESNES, K. A.; KIRCH, W. Effects of physostigmine on scopolamine induced changes in quantitative electroencephalogram and cognitive performance. Human Psychopharmacololy, n. 3 v. 13, p. 199-210, 1998a. Disponível em: https://doi.org/10.1002/ (SICI)1099-1077(199804)13:3<199:AID-HUP974>3.0.CO;2-3. Acesso em: 22 fev. 2020.

ELLMAN, G. L.; COURTNEY K. D.; ANDRES, J.V.; FEATHERSTONE, R. M. A new and rapid colorimetric determination of acetyl-cholinesterase activity. Biochemistry Pharmacology, v. 7, n. 2, p. 88-95, 1961. Disponível em: https://www.sciencedirect.com/science/article/abs/ pii/0006295261901459. Acesso em: 22 fev. 2020.

FIBIGER, H. C. Cholinergic mechanisms in learning memory and dementia: a review of recent evidence, Trends in Neurosciences, v. 14, n. 6, p. 220-223, 1991. Disponível em: https://pubmed. ncbi.nlm.nih.gov/1716012. Acesso em: 22 fev. 2020.

FLOOD, J. F.; CHERKIN, A. Scopolamine effects on memory retention in mice: a model of dementia? Behavior and Neural Biology, v.45, n. 2, p.169-84, 1986. Disponível em: https://www. sciencedirect.com/science/article/abs/pii/S0163104786907508. Acesso em 22 fev. 2020.

GOLD, P. E.; CAHILL, L.; WENK, G. L. Ginkgo biloba: a cognitive enhancer? Psychological. Science in the Public Interest, v. 3, n. 1, p. 2-11, 2002. Disponível em: https://pubmed.ncbi.nlm.nih. gov/26151474. Acesso em 22 fev. 2020.

GRASBY, P. M.; FRITH, C. D.; PAULESU, E.; FRISTON, K. J.; FRACKOWIAK, R. S. J.; DOLAN, R. J. The effect of the muscarinic antagonist scopolamine on regional cerebral blood flow during the performance of a memory task. Experimental Brain Research, v. 104, n. 2, p.337-48, 1995. Disponível em: https://pubmed.ncbi.nlm.nih.gov/7672026. Acesso em: 22 fev. 2020.

IVANOVA, A.; MIKHOVA, B.; NAJDENSKI, H.; TSVETKOVA, I.; KOSTOVA. I. Antimicrobial and cytotoxic activity of Ruta graveolens. Fitoterapia, v. 76, n. 3-4, p. 344-347, 2005. Disponível em: https://pubmed.ncbi.nlm.nih.gov/15890462. Acesso em: 22 fev. 2020.

IZQUIERDO, I.; MEDINA, J. H. Memory formation: The sequence of biochemical events in the hippocampus and its connection to activity in other brain structures. Neurobiology of Learning and Memory, v. 68, n. 3, p. 285-316, 1997. Disponível em: https://pubmed.ncbi.nlm.nih.gov/9398590. Acesso em: 22 fev. 2020.

IZQUIERDO, I. Memória. Artmed, Porto Alegre/RS, 2002.

LANE, C. A.; HARDY, J.; SCHOTT, J. M. Alzheimer's disease. European Journal of Neurology, v. 25, n. 1, p. 59-70, 2018. Disponível em: https://pubmed.ncbi.nlm.nih.gov/28872215. Acesso em: 22 fev. 2020.

LIKHTIK, E.; JOHANSEN, J. P. Neuromodulation in circuits of aversive emotional learning. Nature Neuroscience, v. 22, p. 1586-1597, 2019. Disponível em: https://www.nature.com/articles/ s41593-019-0503-3. Acesso em: 22 fev. 2020.

LIMA, J. A.; COSTA, R. S.; EPIFÂNIO, R. A.; CASTRO, N. G.; ROCHA, M. S.; PINTO, A. C. Geissospermum vellosii stembark: Anticholinesterase activity and improvement of scopolamineinduced memory deficits. Pharmacology, Biochemistry and Behavior, v. 92, n. 3, p. 508-513, 2009. Disponível em: https://pubmed.ncbi.nlm.nih.gov/19463267. Acesso em: 22 fev. 2020.

LOONAT, F.; AMABEOKU, G. J. Antinociceptive, anti-inflammatory and antipyretic activities of the leaf methanol extract of Ruta graveolens L. (Rutaceae) in mice and rats. African Journal of Traditional, Complementary and Alternative Medicines, v. 11, n. 3, p. 173-181, 2014. 
MARQUES, C. P. Análise dos efeitos da morina sobre a memória de reconhecimento e esquiva inibitória em ratos. 50 f. Dissertação (Mestrado em Gerontologia Biomédica) - PUC, Câmpus Porto Alegre, RS, 2004.

MAURYA, R.; SRIVASTAVA, S.; KULSHRESHTA, D.; GUPTA, C. Traditional remedies for fertility regulation. Current Medicinal Chemistry, v. 11, n. 11, p. 1431-1450, 2004. Disponível em: https://pubmed.ncbi.nlm.nih.gov/15180576. Acesso em: 22 fev. 2020.

MCGAUGH, J. L. Involvement of hormonal and neuromodulatory systems in the regulation of memory storage. Annual Review of Neuroscience, v. 12, p. 255-287, 1989. Disponível em: https:// pubmed.ncbi.nlm.nih.gov/2564756. Acesso em: 22 fev. 2020.

MCGAUGH, J. L.; IZQUIERDO, I. The contribution of pharmacology to research on the mechanisms of memory formation. Trends Pharmacological Science, v. 21, p. 208-210, 2000. Disponível em: https://doi.org/10.1016/S0165-6147(00)01473-5. Acesso em: 22 fev. 2020.

MEEPAGALA, K. M.; SCHRADER, K. K.; WEDGE, D. E.; DUKE, S. O. Algicidal and antifungal compounds from the roots of Ruta graveolens and synthesis of their analogs. Phytochemistry, v. 66, n. 22, p. 2689-2695, 2005. Disponível em: https://pubmed.ncbi.nlm.nih.gov/16271733. Acesso em: 22 fev. 2020.

MONTANARI, C. A.; BOLZANI, V. S. Planejamento racional de fármacos baseados em produtos naturais. Química Nova, v. 24, n. 1, p. 105-111, 2001. Disponível em: http://www.scielo.br/scielo. php?pid=S0100-40422001000100018\&script=sci_abstract\&tlng=pt. Acesso em: 22 fev. 2020 .

MONTGOMERY, K. C. The relation between fear induced by novel stimulation and exploratory behavior. Journal of Comparative \& Physiological Psychology, v. 48, n. 4, p. 254-260, 1955. Disponível em: https://pubmed.ncbi.nlm.nih.gov/13252152. Acesso em: 22 fev. 2020.

MORRIS, R. Developments of a water-maze procedure for studying spatial learning in the rat. Journal Neuroscience Methods, v. 11, n. 1, p. 47-60, 1984. Disponível em: https://pubmed.ncbi. nlm.nih.gov/6471907. Acesso em: 22 fev. 2020.

MOSS, M.; COOK, J.; WESNES, K. Aromas of rosemary and lavender essential oils differentially affects cognition and mood in healthy adults. International Journal Neuroscience, v. 38, n. 1, p. 113-115, 2003. Disponível em: https://www.sciencedirect.com/science/article/pii/ S2090506816301944. Acesso em: 22 fev. 2020.

MOSSI, A. J.; ASTOLFI, V.; KUBIAK, G.; LERIN, L.; ZANELLA, C.; TONIAZZO, G.; DE OLIVEIRA, D.; TREICHEL, H.; DEVILLA, I. A.; CANSIAN, R.; RESTELLO, R. Insecticidal and repellency activity of essencial oil of Eucalyptus sp. against Sitophilus zeamais Motschulsky (Coleoptera, Curculionidae). Journal of the Science of Food and Agriculture, v. 91, n. 2, p. 273 277, 2011. Disponível em: https://pubmed.ncbi.nlm.nih.gov/20945512. Acesso em 22 fev. 2020.

MOSSI, A. J.; MAZUTTI, M. A.; CANSIAN, R. L.; DE OLIVEIRA, D.; DE OLIVEIRA, J. V.; DALLAGO, R.; ORLOV, O. L.; TREICHEL, H. Variabilidade química de compostos orgânicos voláteis e semivoláteis de populações nativas de Maytenus ilicifolia. Química Nova, v. 33, n. 5, p. 1067-1070, 2010. Disponível em: http://www.scielo.br/scielo.php?pid=S010040422010000500011\&script=sci_abstract\&tlng=pt. Acesso em: 22 fev. 2020.

MOURÃO JÚNIOR, C. A.; FARIA, N. C. Memory. Psicologia: Reflexão e Crítica, v. 28, p. $780-$ 788, 2015. Disponível em:

NEMATOLAHI, P.; MEHRABANI, M.; KARAMI-MOHAJERI, S.; DABAGHZADEH, F. Effects of Rosmarinus officinalis $L$. on memory performance, anxiety, depression, and sleep quality in university students: A randomized clinical trial. Complementary Therapies in Clinical Practice, v. 30, p. 24-28, 2018. Disponível em: https://www.sciencedirect.com/science/article/abs/pii/ S1744388117304723. Acesso em: 22 fev. 2020. 
NIEBER, K. The Impact of Coffee on Health. Planta Medica, v. 83, n. 1, p. 1256-1263, 2017. Disponível em: https://pubmed.ncbi.nlm.nih.gov/23465359-the-impact-of-coffee-on-health/. Acesso em: 22 fev. 2020.

NOWOTNY, P.; KWON, J. M.; GOATE, A. M. Alzheimer disease encyclopedia of life sciences. Nature Publishing Group, 2001. Disponível em: http://www.ufrgs.br/ppgneuro/artigos/Alzheimer_ ELS2003.pdf. Acesso em: 22 fev. 2020.

OLIVA, A.; MEEPAGALA, K. M.; WEDGE, D. E.; HARRIES, D.; HALE, A. L.; ALIOTTA, G.; DUKE, S. O. Natural fungicides from Ruta graveolens L. leaves, including a new quinolone alkaloid. Journal of Agricultural and Food Chemistry, v. 51, n. 4, p.890-896, 2003. Disponível em: https://pubmed.ncbi.nlm.nih.gov/12568545-natural-fungicides-from-ruta-graveolens-l-leavesincluding-a-new-quinolone-alkaloid/. Acesso em: 22 fev. 2020.

PERRY, N.; COURT, G.; BIDET, N.; COURT, J.; PERRY, E. European herbs with cholinergic activities: potential in dementia therapy. International Journal of Geriatric Psychiatry, v. 11, p.1063-1069, 1996. Disponível em: https://doi.org/10.1002/(SICI)10991166(199612)11:12<1063::AID-GPS532>3.0.CO;2-1. Acesso em: 22 fev. 2020.

PETERSON, G. L. A simplification of the protein assay method of Lowry et al. which is more generally applicable. Analytical Biochemistry, v. 83, n. 2, p. 346-56, 1977. Disponível em: https:// pubmed.ncbi.nlm.nih.gov/603028. Acesso em: 22 fev. 2020.

PREDIGER D. S. R.; FERNANDES S. M.; RIAL, D. WOPEREIS. S.; PEREIRA V.; BOSSE S.T. SILVA, B. C.; CARRADORE R.S.; MACHADO M. S.; FILHO, C. V.; CAMPOS, C. L. Effects of acute administration of the hydroalcoholic extract of mate tea leaves (Ilex paraguariensis) in animal models of learning and memory. Journal of Ethnopharmacology, v. 120, n. 3, p. 465-473, 2008. Disponível em: https://pubmed.ncbi.nlm.nih.gov/18948179. Acesso em: 22 fev. 2020.

QUILLFELDT, J. A. Behavioral Methods to Study Learning and Memory in Rats. (Org.). Animal Models as Tools in Ethical Biomedical Research, p. 227-269, 2010.

RAGHAV, S. K.; GUPTA, B.; AGRAWAL, C.; GOSWAMI, K.; DAS, H. R. Anti-inflammatory effect of Ruta graveolens L. in murine macrophage cells. Journal of Ethnopharmacology, v. 104, n. 1-2, p. 234-239, 2006. Disponível em: https://pubmed.ncbi.nlm.nih.gov/16207519. Acesso em: 23 fev. 2020.

RESTELLO, R. M.; MENEGATT, C.; MOSSI, A. J. Efeito do óleo essencial de Tagetes patula L. (Asteraceae) sobre Sitophilus zeamais Motschulsky (Coleoptera, Curculionidae). Revista Brasileira de Entomologia, v. 53, n. 2, p. 304-307, 2009. Disponível em: http://www.scielo.br/scielo. php?script=sci_arttext\&pid=S0085-56262009000200015. Acesso em: 23 fev. 2020.

ROESLER, R.; SCHRÖDER, N.; VIANNA, M. R. Differential involvement of hippocampal and amygdalar NMDA receptors in contextual and aversive aspects of inhibitory avoidance memory in rats. Brain Research, v. 975, n. 1-2, p. 207-213, 2003. Disponível em: https://pubmed.ncbi.nlm.nih. gov/12763609. Acesso em: 23 fev. 2020.

RUSSO, P.; FRUSTACI, A.; DEL BUFALO, A.; FINI, M.; CESARIO, A. From traditional European medicine to discovery of new drug candidates for the treatment of dementia and Alzheimer's disease: acetylcholinesterase inhibitors. Current Medicinal Chemistry, v. 20, p. 976-983, 2013. Disponível em: https://pubmed.ncbi.nlm.nih.gov/23210783. Acesso em: 23 fev. 2020.

SANDRY, J. Working memory and memory loss in neurodegenerative disease. Neurodegenerative Disease Management, v. 5, n. 1, p. 1-4, 2015. Disponível em: https://pubmed.ncbi.nlm.nih. gov/25711447. Acesso em: 23 fev. 2020.

SCALBERT, A.; WILLIAMSON, G. Dietary intake and bioavailability of polyphenols. Journal of Nutrition, v. 130, p. 2073-2085, 2000. Disponível em: https://pubmed.ncbi.nlm.nih.gov/10917926. Acesso em: 23 fev. 2020. 
SCREMIN, O. U.; LI, M. G.; SCREMIN, A. M.; JENDEN, D. J. Cholinesterase inhibition improves blood flow in the ischemic cerebral cortex. Brain Research Bulletin, v. 44, n. 1, p.59-70, 1997. Disponível em: https://pubmed.ncbi.nlm.nih.gov/8978935. Acesso em: 23 fev. 2020.

SEFIDKON, F.; ABBASI, K.; JAMZAD, Z.; AHMADI, S. The effect of distillation methods an stage of plant growth on the essential oil content and composition of Satureja rechingeri Jamzad. Food Chemistry, v. 100, p. 1054-1058, 2007. Disponível em:

SEN, T.; SAMANTA, S. K. Medicinal plants, human health and biodiversity: a broad review. Advances in Biochemical Engineering / Biotechnology, v. 147 p. 59-110. 2015. Disponível em: https://pubmed.ncbi.nlm.nih.gov/25001990. Acesso em: 22 fev. 2020.

SMITH, G. Animal models of Alzheimer's disease: experimental cholinergic denervation. Brain Research Reviews, v. 13, n. 2, p. 103-118, 1988. Disponível em: https://www.sciencedirect.com/ science/article/abs/pii/0165017388900161. Acesso em: 22 fev. 2020.

SQUIRE, L. R.; KANDEL, E. R. Memória: da mente às moléculas. Porto Alegre/RS: Artmed, 2003. STASHENKO, E. E.; ACOSTA, R.; MARTÍNEZ, R. High-resolution gas chromatographic analysis of the secondary metabolites obtained by subcritical-fluid extraction from Colombian rue (Ruta graveolens L.). Journal of Biochemical and Biophysical Methods, v. 44, n. 1-3, p. 379-390, 2000. Disponível em: https://www.sciencedirect.com/science/article/abs/pii/S0165022X00000798. Acesso em: 22 fev. 2020.

STREGE, M. A. High-performance liquid chromatographic- electro spray ionization mass spectrometric analyses for the integration of natural products with modern high-throughput screening. Journal of Chromatography B: Biomedical Sciences and Applications, v. 725, n. 1-2, p. 67-78, 1999. Disponível em: https://www.sciencedirect.com/science/article/pii/ S0378434798005532. Acesso em: 22 fev. 2020.

TAN, M.S.; YU, J.T.; TAN, C.C.; WANG, H. F.; MENG, X.F.; WANG, C., JIANG,T.; XI-ZHU,C.; TAN, L. Efficacy and adverse effects of ginkgo biloba for cognitive impairment and dementia: a systematic review and meta-analysis. Journal of Alzheimer's Disease, v. 44, n. 2, p. 589-603. 2015. Disponível em: https://pubmed.ncbi.nlm.nih.gov/25114079. Acesso em: 22 fev. 2020.

W.H.O. World Health Organization. Programme on traditional medicine. Guidelines for the assessment of herbal medicines, v. 28, p. 13-19, 1991. Disponível em: https://apps.who.int/iris/ handle/10665/58865. Acesso em: 19 fev. 2020.

TAYLOR, P.; BROWN, J. H. Basic Neurochemistry: molecular, cellular and medical aspects. 5. ed. New York: Raven, p. 213-260, 1994.

YAACOB, K. B.; ABDULLAH, C. M.; JOULAIN, D. Essential oil of Ruta graveolens L. Journal Essential Oil Research, v. 1, p. 203-207, 1989. Disponível em: https://doi.org/10.1080/10412905.19 89.9697787. Acesso em: 22 fev. 2020.

ZANELLA, C. A.; TREICHEL, H.; CANSIAN, R. L; ROMAN, S. S. The effects of acute administration of the hydroalcoholic extract of rosemary (Rosmarinus officinalis L.) (Lamiaceae) in animal models of memory. Brazilian Journal of Pharmaceutical Science, v. 48, n. 3, p. 389-397, 2012. Disponível em: http://www.scielo.br/scielo.php?script=sci_arttext\&pid =S1984-82502012000300005. Acesso em: 22 fev. 2020.

ZARGARI, A. Medicinal Plants. Tehran University Press, Tehran, in Persian, v. 3, 6. ed. 1990. 